Orientalia Christiana Cracoviensia 4 (2012), s. 59-75

DOI: http://dx.doi.org/10.15633/ochc.1035

\author{
Jacek Bonarek \\ Uniwersytet Jana Kochanowskiego w Kielcach \\ Filia w Piotrkowie Trybunalskim
}

\title{
Ромеи - только жители империи или народность in statu nascendi?
}

Вопрос чувства национальной общности в многоэтнических государствах очень труден, он стар, как и возникновение самого народа. Повсеместно считается, что национальное сознание формировалось на переломе XVIII и XIX столетий, когда в западном полушарии образовывался ряд новых государств, с самого начала своего существования имеющих многоэтнический характер ${ }^{1}$.

${ }^{1}$ Первым из них, несомненно, являются Соединённые Штаты, образовавшиеся уже в конце XVIII в., а среди остальных можно назвать: Мексику (1821) или Бразилию (1822). Эти три государства кажутся интересными, как пример образований, которые до настоящего времени не завершили полностью процесс создания народности, особенно борясь с проблемой наплыва очередных волн иммиграции. Также всё три применили одну и ту же модель унифицирования общественности, не требующую навязывания силой чувства национальной принадлежности, однако, де-факто, не оставляющую выбора, так как, чтобы полностью пользоваться правами гражданина и получить возможность повышения по службе, нужно усвоить язык, обычаи и религию доминирующей группы. Это было особенно заметно, и отчасти все еще имеет место, в Соединенных Штатах, которые из языка и англосаксонской культуры, в меньшей степени из религии, сделали костяк американской нации. Несколько иначе выглядела ситуация в многонациональных государства Старого Мира в XIX веке (напр. Россия, Германия), так как в этих монархиях доминирующая этногруппа навязывала не только свой язык или культуру, но и этническую принадлежность. В свою очередь, в XX веке перед похожей проблемой, как в США или Мексике, стали также федеративные государства Европы коммунистического режима: СССР или Югославия. Однако у них эта проблема не была решена и не сформировался общегосударственный тренд, который мог привести к возникновению новой национальной общности, хотя в Югославии появилась группа людей называющих себя Югословенами, однако она была немногочисленной и в основном состояла из потомства смешанных пар; напр. E. Gellner, Nations and nationalism, Oxford 1983; E. J. Hobsbawm, Nations and nationalism since 1780. Programme, myth, reality, Cambridge 1990; B. Anderson, Imagined communities. Reflections on the origin and spread of nationalism, London-New York 1991, 
Происходящие в то время процессы можно исследовать, используя многочисленные письменные источники, в которых эти вопросы затрагивались самими заинтересованными в них. Но остаётся открытым вопрос, как можно описать похожий процесс образования народности в европейских государствах средневековой эпохи. Естественно, сразу же возникает затруднение, можно ли было вообще говорить о национальном чувстве в те времена. Однако, кажется, что мнение, допускающее существование народности в средневековье, уже получило прочную позицию в литературе ${ }^{2}$. Стоит, все-таки, подчеркнуть, что это была бы так называемая политическая народность, охватывающая высшие слои обществ, а также то, что вопрос народности касался бы, в основном, государств образовавшихся на базе одной, конкретной этнической группы ${ }^{3}$.

В свою очередь, Византия, наследник Римской империи, является отличным примером многоэтнического государства средневековой Европы. Стоит также подчеркнуть, что византийцем, то есть ромеем, официально был каждый житель, признающий ортодоксальное вероисповедание и принадлежащий к христианско-греческой культуре. Таким образом

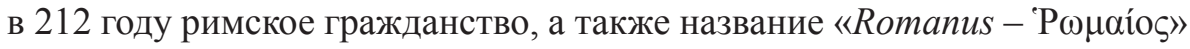
распространялись на всех вольных жителей Империи. Это имело далеко идущие последствия и прочно вписало понятие «ромей» в словарный

T. H. Eriksen, Ethnicity and nationalism, London 1993; G. I. Mirsky, On ruins of empires. Ethnicyty and nationalism in the former Soviet Union, London 1997.

${ }^{2}$ B. Zientara, Nationale Strukturen des Mittelalters. Ein Versuch zur Kritik der Terminologie des Nationalbewusstseins unter besonderer Berücksichtigung osteuropäischer Literatur, „Saeculum” 32 (1981), c. 301-316; idem, La conscience nationale en Europe occidentale au Moyen Age. Naissance et mécanisme du phénoméne, „Acta Poloniae Historica” 46 (1982), c. 5-30; idem, Świadomość narodowa w Europie Zachodniej w średniowieczu. Powstanie i mechanizmy zjawiska, [в:] Państwo, naród, stany w świadomości wieków średnich, red. A. Gieysztor, S. Gawlas, Warszawa 1990, c. 11-26; idem, Świt narodów europejskich. Powstanie i rozwój świadomości narodowej na obszarze Europy pokarolińskiej, Warszawa 1996; также: G. G. Coulton, Nationalism in the Middle ages, „Cambridge Historical Journal” 5 (1935), c. 15-40; H. Koht, The dawn of nationalism in Europe, „The American Historical Review” 52 (1947), c. 265-280; B. Guenée, État et nation en France au Moyen Age, „Revue Historique” 237 (1967), c. 17-30; K. F. Werner, Les nations et le sentiment national dans l'Europe médiévale, „Revue Historique” 244 (1970), c. 285-304; S. Bagge, Nationalism in Norway in the Middle ages, „Scandinavian Journal of History” 20 (1995), c. 1-18; P. J. Geary, The myth of nations: the medieval origins of Europe, Princenton 2003.

${ }^{3}$ Хорошим примером может быть формирование испанского сознания, в VI-VIII веках, на основе готских традиций, однако оно было прервано арабским нашествием; S. Teillet, Des Goths à la nation gothique, Paris 1984, c. 461-644; M. Salamon, "Ojczyzny» plemion barbarzyńskich okresu Wędrówki Ludów, [в:] Pamiętnik XV Powszechnego Zjazdu Historyków Polskich, I, 1, red. J. Staszewski, Gdańsk-Toruń 1995, c. 176; L. A. G. Moreno, Spanish Gothis consciousness among the Mozarabs in Al-Andalus (VIII-X ${ }^{\text {th }}$ centuries), [в:] The Visigoths. Studies in culture and society, ed. A. Ferreiro, Leiden-Boston-Köln 1998, s. 303-304; также: R. Collins, Visigothic Spain 409-711, Oxford 2006, c. 239-246. 
состав языка и психику жителей восточной части многоэтнической Им-

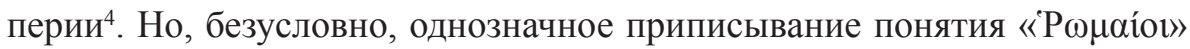
конкретной этнической группе натолкнулось бы на многочисленные препятствия, связанные с флуктуационным характером этого названия. Так в IV-VI веках это понятие охватывало, в частности, греков, сирийцев, египтян, итало-романцев или афро-романцев, в свою очередь в VII-X/XI веках, ромеями, кроме греков, называли также славян, болгар и армян, но в последующих веках в византийском обществе появлялись также латиняне, турки и даже албанцы ${ }^{5}$. Стоит всё-таки повторно подчеркнуть, что многоэтническая Византия основывалась на римском праве, христианском вероисповедании и греческой культуре, а жители Империи считали себя законными преемниками «civium Romanorum».

Здесь следует подчеркнуть, что, в течение всего времени существования Византии, название «ромей» имело также общественный характер и обозна-

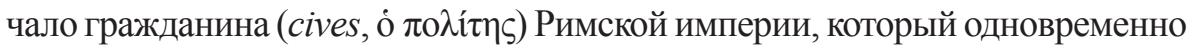
был подданным (subiectus, ó vंли́коо $)$ императора ${ }^{6}$. Впрочем, позднее, это второе определение начало преобладать и вероятно стало причиной того, что с течением времени не все подданные императора стали считаться

\footnotetext{
${ }^{4}$ Corpus Iuris Civilis, Digesta, (Ulpianus) I, V, 17: in orbe Romano qui sunt ex constitutione imperatoris Antonini cives Romani effecti sunt; C. A. Trypanis, Les termes «Romios», «Romiossini» et «Romania» pour les Grecs, [в:] Da Roma alla terza Roma, 3: Popoli e spazio romano tra diritto e profezia, Napoli 1986, c. 432-433; A. Łukaszewicz, Aegyptiaca Antoniniana. Działalność Karakalli w Egipcie (215-216), Warszawa 1993, c. 19; E. Chrysos, The political identity in late antiquity and early Byzantium, [в:] Byzantium. Identity, image, influence, ed. C. Fledelius, Copenhagen 1996, c. 15-16.

${ }^{5}$ О многоэтничности Византии смотреть напр. Р. Charanis, On the ethnic composition of byzantine Asia Minor in the thirteenth century, [в:] Studies offered in Honour of St. Kyriakides (Prosphora eis Stilpona P. Kyriakiden), Thessalonica 1953, c. 140-147; idem, The transfers of population as a policy in the Byzantine Empire, „Comparative Studies in Society and History an International Quarterly" 3 (1960) 1, c. 140-154; idem, How Greek was the Byzantine Empire?, „Bucknell Review” 11 (1963), c. 101-116; G. Dagron, Aux origines de la civilisation byzantine: Langue de culture et langue d'État, ,Revue Historique” 241 (1969), c. 49, 50-54; A. E. Vacalopoulos, Origins of the Greek nation. The Byzantine period, 1204-1453, New Brunswick 1970, с. 1-16; Г. Г. Литаврин, Византийское общество и государство в X-XI в6, Москва 1977, c. 156-177; D. A. Zakythinos, Byzance: État national ou multinational?, „Deltion Christianikis Archaiologikis Etaireias" 4 (1980-1981) 10, c. 29-52; E. Wipszycka, Le nationalisme a-t-il existè dans l'Egypte byzantine?, „The Journal of Juristic Papyrology” 22 (1992), c. 83-128.

${ }^{6} \mathrm{~W}$. S. Thurman, The application of subiecti to Roman citizens in the imperial laws of the later Roman Empire, „Klio” 52 (1970), s. 453-463; C. Dupont, Sujets et citoyens sous le Bas-Empire romain de 312 à 565 après Jésus Christ, „Revue international des droits de l'antiquité” 20 (1973), s. 325-339; F. Goria, Romani, cittadinanza ed estensione della legislazione imperiale nelle costituzioni di Giustiniano, [в:] Da Roma alla terza Roma, 2: La nozione di "Romano" tra cittadinanza e universalità, Napoli 1984, c. 322.
} 
ромеями ${ }^{7}$. В свою очередь, открытым остаётся также вопрос - имел ли в Византии этноним «ромей» исключительно упомянутое общественное значение, без этнического оттенка ${ }^{8}$.

Возвращаясь к вопросу многоэтничности Империи, следует подчеркнуть, что разнородная этническая ситуация, изменения границ, такие как наплыв или же завоевание очередного народа, ясно показывают, что в Византии преобладали земли заселенные различными племенами, что затрудняет ответ на вопрос, можно ли говорить о существовании, или даже вернее формировании, ромейской народности. Однако, пользуясь примером новых американских государств, можно попытаться разобрать значения трёх элементов: языка, культуры и вероисповедания ромеев, а также их роли в возможном процессе образования народности, что даст возможность хотя бы частично ответить на поставленный выше вопрос.

Кажется, что всё же греческий язык ${ }^{9}$ был важным фактором ромейской общности ${ }^{10}$, так как он преобладал на территориях империи с VII-VIII века, когда были утрачены земли, на которых говорилось на латыни, коптском

${ }^{7}$ Хорошим примером кажется Григорий Пакуриан, гордящийся своим грузинского происхождением и носящий один из высочайших санов Византим ХІ столетия - Великий Доместик Запада; Р. Gautier, Le typicon du sébaste Grégoire Pakurianos, „Revue des Etudes Byzantines” 42 (1984), с. 21; тоже: Г. Г. Литаврин, Византийское общество ..., с. 170; P. Charanis, Romiosyne as a concept for the interpretation of Greek history, „Byzantine Studies/ Etudes Byzantines" 8-12 (1981-1985), c. 63; G. Dagron, Formes et fonctions du pluralisme linguistique à Byzance (IXe-XII ${ }^{e}$ siècle), „Travaux et Mémoires” 12 (1994), c. 233; P. Magdalino, Hellenism and Nationalism in Byzantium, [в:] idem, Tradition and Transformation in Medieval Byzantium, Aldershot 1991, XIV, c. 9.

${ }^{8}$ Напр. Г. Г. Литаврин, Византийское общество..., с. 163, 166-167; A. Christophilopoulou, Byzantine history, II: 610-867, Amsterdam 1993, c. 293-294; A. Cameron, The Byzantines, Oxford 2006, c. 8.

9 Здесь стоит упомянуть, что византийцы называли греческий язык ромейским языком. Примером может быть описание переговоров проводимых болгарским царем Симеоном с императором Романом Лакапином в 924 году, когда отряды болгар поприветствовали своего властителя как императора на ромейском языке ( приведённый Анной Комниной пересказ о турках просящих о помиловании по-ромейски

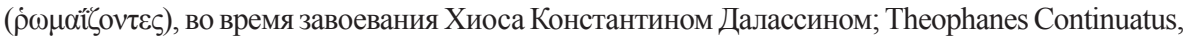
Ioannes Cameniata, Symeon Magister, Georgius Monachus, ed. I. Bekker, Bonnae 1838, c. 407; Symeonis Magistri et Logothetae, Chronicon, rec. S. Wahlgren, Berlin-New York 2006, c. 322 (CFHB, XLIV/1); Ioannis Scylitzae, Synopsis Historiarum, rec. I. Thurn, Berlin-New York 1973, c. 219-220 (CFHB, V); Annae Comnenae, Alexias, rec. D. R. Reinsch, A. Kambylis, Berlin-New York 2001, с. 223 (CFHB, XL/1).

${ }^{10}$ О сложной языковой ситуации в Византии см. напр. G. Dagron, Aux origines..., c. 54-56; idem, Formes..., c. 219-240; H. Mihăescu, Byzance-foyer du Rayonnement de la culture romaine et de la langue latine dans le sud-est de l'Europe, „Byzantina” 6 (1974), c. 217-226; И. Ћурић, Ромејски говор и језик Константина VII Порфирогенита, „Зборник Радова Византолошког Института" 24-25 (1986), с. 109-137; N. Oikonomidès, L' «Unilinguisme»

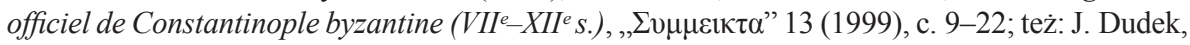
Patrycjusz Swen (Sfenis) w bizantyńskiej wieży Babel, [в:] Mundus hominis - cywilizacja, kultura, 
языке или по-сирийски ${ }^{11}$. Значит, не следует недооценивать значения этого элемента, несмотря на то, что многоязычность была в империи нормальным делом, так как без беглого знания греческого было невозможно ни общественное повышение по службе, ни политическая карьера ${ }^{12}$. Отождествление «ромейскости» с владением греческим языком было так сильным, что император Михаил III в IX веке даже назвал латынь варварским языком, что вызвало изумление папы римского Николая I, который задал Михаилу вопрос, почему тогда он считает себя императором римлян ${ }^{13}$. Значение языка, как формы отличия, улавливали также находящиеся в Византии иностранцы, что показывает пример диалога Лиутпранда Кремонского, посланника Оттона I Великого, с императором Никифором II Фокой. Когда император упрекнул Лиутпранда, что Оттон нарушил границы Византии в Италии, тот ответил, что хоть это и есть часть империи, но, судя по языку тамошних жителей, те территории принадлежат Итальянскому королевству ${ }^{14}$. Значит, в этом случае, язык является определителем общности и показывает, что жители итальянских провинций ромейской империи не обязательно должны считаться ромеями ${ }^{15}$.

В свою очередь одно из самых любопытных и главных сведений, говорящее о значении языка для формирующейся общности ромеев, находится во фрагменте Алексиады, в котором Анна Комнина упоминает о школе в Мангане, где вместе с ромеями, изучающими классические

natura, red. S. Rosik, P. Wiszewski Wrocław 2006, c. 291-305 (Acta Universitatis Wratislavensis, 2966, Historia CLXXV).

${ }^{11}$ P. Charanis, Ethnic changes in seventh-century Byzantium, „Dumbarton Oaks Papers” 13 (1959), c. 25-44; G. Dagron, Aux origines..., c. 34-36; D. A. Zakythinos, Byzance..., c. 31.

12 J. Herrin, Byzantium: the suprising life of a Medieval Empire, London 2007, c. 248-249.

${ }^{13}$ Epistolae Karolini aevi (IV), Hrsg. E. Dümmler, E. Perels, Berlin 1974 (Monumenta Germaniae Historica. Epistolae, 6), c. 459; G. Dagron, Formes..., c. 220.

${ }^{14}$ Die Werke Liutprands von Cremona, Hrsg. J. Becker, Hannower und Leipzig 1915, c. 179.

${ }^{15}$ Notabene, похожее отличие можно найти также в византийских источниках. Например, Иоанн Скилица в своем «Обозрении истории» вспоминает, что, во время царствования Василия I Македонянина, когда арабы овладели почти всей Сицилией и продолжали наступление, император, желая остановить экспансию арабов, поручил командование Никифору Фоке Старшему, который, правда, вытеснил захватчиков из Италии, но, вместе с тем, подвластные ему солдаты взяли в неволю многих тамошних жителей, которых Иоанн Скилица называет 'I $\alpha \lambda$ ol, что однако можно было бы объяснить местным названием

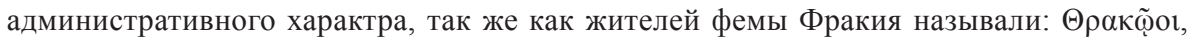

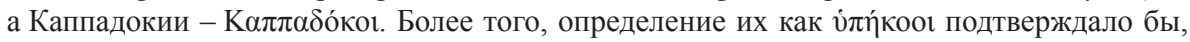
что они являются полноправной частью византийской общественности. Существенным кажется также то, что жители Италии, те 'І $\alpha \lambda$ ої были довольно специфическим образом

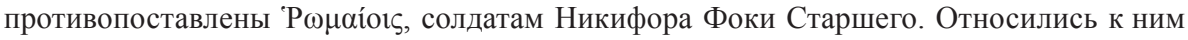
как к населению абсолютно чужому, которое может быть даже рабами ромеев, значит, тем самым можно признать, что быть подданными императора было не достаточно, чтобы считаться ромеями (Ioannis Scylitzae, Synopsis Historiarum, c. 262-263). 
тексты $^{16}$, греческий язык учили латины, скифы и эллины. Анна Комнина затронула там два, как кажется, существенных вопроса. Первый - это объяснимое изучение греческого языка иностранцами: латинами, то есть пришельцами с запада, многочисленными во времена Комнинов, а также скифами, по-видимому европейскими кочевниками (куманами, печенегами), также под этим термином могли быть и русы. Изучение этими людьми греческого языка было условием sine qua non, чтобы стать полноправными членами ромейского общества ${ }^{17}$. Вторым важным вопросом является факт, что для Анны Комниной, скорее всего, не существовал знак равенства между ромеем и греком, несмотря на то, что они говорили на одном языке ${ }^{18}$. Значит, примененный Комниной этноним «эллин», следует понимать, в этнических категориях, как синоним названия грек ${ }^{19}$. Кроме того, упомянутые Комниной, латин, скиф и эллин характеризуются общим свойством, они только изучают ту культуру, которая уже есть у ромея. Ромей, в противоположность эллину, а также скифу и латину, что уже однако понятно, не учит греческий, он только лишь изучает, то есть исследует и старается понять, тексты древних философов и поэтов. Итак, в этом коротком отрывке из Алексиады, ромей представляется как человек высокой культуры.

В связи с вышеуказанным фрагментом, стоит вспомнить именно о культуре, как очередном элементе ромейской общности. Несомненно, ромейская культура, понимаемая как система идей, знаков и способа поведения, отличалась от других, но разница была мало заметной. Опять примером может быть фрагмент произведения Лиутпранда Кремонского, который перечисляет свойства характеризующие ромеев, а также подчёркивает отличие их одежды ${ }^{20}$. Кажется, что, несмотря на явно негативное звучание этих описаний, слова Лиутпранда свидетельствуют о явном отличии ромеев. В свою очередь, одно из радикально выраженных убеждений о культуре,

${ }^{16}$ Annae Comnenae, Alexias, c. 484-485.

${ }^{17}$ Стоит вспомнить также личность византийского офицера Просуха, о котором Иоанн

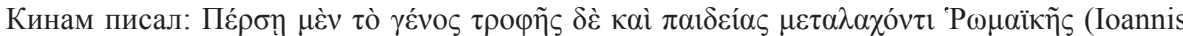
Cinnami, Epitome rerum ab Ioanne et Alexio Comnenis gestarum, rec. A. Meineke, Bonnae 1836, с. 73); также: C. M. Brand, The Turkish element in Byzantium, eleventh-twelfth century, „Dumbarton Oaks Papers” 43 (1989), c. 18; P. Bádenas, L'intégration des Turcs dans la société

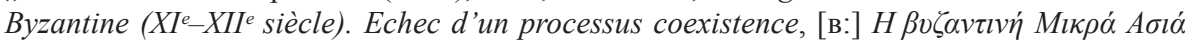

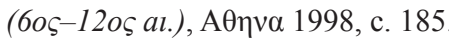

${ }^{18} \mathrm{O}$ различиях между устной и письменной речи в Византии: R. M. Dawkins, The Greek language in the Byzantine period, [в:] Byzantium. An introduction to East Roman civilisation, ed. N. H. Baynes, H. St. L. B. Moss, Oxford 1948, c. 252-267; N. Toufexis, Diglossia and register variation in Medieval Greek, „Byzantine and Modern Greek Studies” 32 (2008), c. 203-217.

${ }^{19}$ См. также: R. Beaton, Antique nation? «Hellenes» on the eve of Greek independence and in twelfth-century Byzantium, ,Byzantine and Modern Greek Studies” 31 (2007), c. 88-90.

${ }^{20}$ Die Werke Liutprands von Cremona, c. 196-197. 
как определителе отличия ромеев, можно найти в трактате императора Константина Багрянородного, озаглавленном «De administrando imperio», где он сформулировал запрет браков между византийский двором и представителями других народов, ссылаясь как раз на разницу культур и языков и подчёркивая существование отдельной ромейской культуры ${ }^{21}$. Похожая формулировка, говорящая о ромейских обычаях и образе жизни, появляется во время описания боев с печенегами весной 1047 года. Именно тогда печенежский ренегат Кеген предложил истребить своих сдавшихся ромеям побратимов, но с этим предложением не согласились византийские вожди, которые назвали его варварским, нечестивым и недостойным ромейской культуры $^{22}$. Отклонение предложения патрикия Кегена ${ }^{23}$ подсказывает, что самого факта принадлежности к титулованным элитам не достаточно, чтобы стать ромеем не только по названию. Чтобы стать ромеем, необходимо было быть не только ортодоксальным христианином, подданным императора, жителем Империи, но нужно было ещё и приспособиться к определённому стилю жизни. Подчёркивание отличия и превосходства ромейской

${ }^{21}$ Constantinus Porphyrogenitus, De Administrando Imperio, ed. Gy. Moravsik, R. J. H. Jenkins Washington 1967, с. 70, 74 (CFHB, I); см. также: P. Magdalino, Hellenism..., c. 5; R. Macrides, Dynastic marriages and political kinship, [в:] Byzantine diplomacy. Papers from the Twenty-fourth Spring Symposium of Byzantine Studies, Cambridge, March 1990, ed. J. Shepard, S. Franklin, Aldershot 1992, c. 266-268; E. Malamut, Les peuples étrangers dans l'idéologie impériale. Scythes et Occidentaux, [в:] L'étranger au Moyen Âge. Actes du XXX Congrès de la SHMESP (Göttingen, 1999), Paris 2000, c. 119-120; V. Tăpkova-Zaimova, Y-a-t-il une notion de minorité

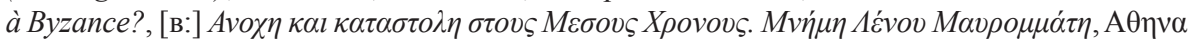
2002, c. 363-365.

${ }^{22}$ Ioannis Scylitzae, Synopsis Historiarum, c. 459; см. тоже: В. Г. Василевский, Византия и печенеги (1048-1094), „Журнал Министерства Народного Просвещения” 164 (1872) № 11 и 12, с. 125-127; G. Schlumberger, L'épopée byzantine à la fin du dixième siècle, t. 3, Paris 1905, c. 571; P. Diaconu, Les Petchénègues au Bas-Danube, Bucareşt 1970, c. 62-65; В. Златарски, История на българската държава през средните векове, София 1972, c. 91-92; E. Malamut, L'image byzantine des Petchénègues, „Byzantinische Zeitschrift” 88 (1995), c. 118-123; idem, Les peuples..., c. 123-124; P. Stephenson, Byzantium's Balkan frontier: a political study of the Northern Balkans, 900-1204, Cambridge 2000, c. 90.

${ }^{23}$ Кеген, после получении согласия на поселение на землях Империи, был окрещен, а затем он получил ряд титулов и санов (патрикий, магистрос, архонт), о чем свидетельствуют повествовательные источники (Ioannis Scylitzae, Synopsis Historiarum, c. 456) и сфрагистик (печать Иоанна Кегена: Corpus of Byzantine seals from Bulgaria, I, ed. I. Jordanov, Sofia 2003, c. 138); P. Diaconu, Les Petchénègues..., c. 57-58; I. Jordanov, Sceau d'archonte de Patzinakia du XIe siècle, „Etudes Balkaniques” 2 (1992), c. 79-82; E. Malamut, L'image..., c. 118-119; J. Dudek, Pieczęć magistra Jana Kegena jako wyraz polityki Bizancjum wobec stepowców w połowie XI w., [в:] «Causa creandi»: o pragmatyce źródła historycznego, red. S. Rosik, P. Wiszewski Wrocław 2005, c. 327-343 (Acta Universitatis Wratislaviensis. Historia); idem, Ludy tureckie w Cesarstwie Bizantyńskim w latach 1025-1097, „Balcanica Posnanensia” 14 (2007), c. 111-115; idem, Nowa Patzynakia pomiędzy Wschodem i Zachodem. Z zapomnianych dziejów małego ludu, [w:] Opuscula archaeologica: opera dedicata in professorem Thaddeum Malinowski, red. W. Dzieduszycki, Zielona Góra 2007, c. 104-125. 
культуры можно найти также в переписке Феофилакта - архиепископа Охриды, который часто жаловался на отсталость и бескультурье места, в котором ему пришлось жить ${ }^{24}$. Более того, он называет тамошних болгар, ортодоксальных христиан, с 1018 года подданных императора, варварами, не признавая тем самым их принадлежность к ромеям ${ }^{25}$. Похожие слова о превосходстве ромейской культуры, но теперь над культурой Запада, высказывает также упоминавшаяся уже Анна Комнина в описаниях участников I-го крестового похода ${ }^{26}$. Разумеется, это, прежде всего, признак ксенофобии, которую, однако, можно связывать с возрастающим чувством общности и отличия ромеев ${ }^{27}$.

${ }^{24}$ Theophylacti Achridensis, Epistulae, rec. P. Gautier, Thessalonique 1986, c. 147, 171, 213 , 243, 315, 435, 531 (CFHB, XVI/2); см. также: Г. Г. Литаврин, Болгария и Византия в XI-XII вв., Мосвка 1960, с. 369-371; idem, Византийское общество..., с. 168.

${ }^{25}$ Напр., в письме Великому Доместику Адриану Комнину, когда жалуется, что служит...

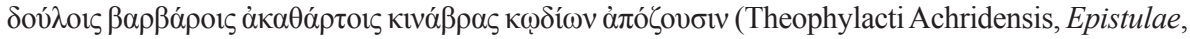
c. 145, а также: 293, 295, 317). Стоит упомянуть, что Михаил Пселл тоже называет болгар варварами, несмотря на то, что отлично знает о том, что они давно уже часть византийского государства; Michel Psellos, Chronographie, ed. E. Renauld, t. 1, Paris 1926, с. 76, 77.

${ }^{26}$ Описание Анны Комниной является конфронтацией того, что в Византии слышали о людях Запада, с тем, что тогда могли заметить, то есть их варварство, высокомерие, жадность, нелояльность, жестокость (Annae Comnenae, Alexias, c. 296-321); похожий образ крестоносцев можно найти также у других авторов, описывающих крестовый поход: Kinnamos, c. 67, 70-71; Nicetae Choniatae, Historia, rec. J. A. van Dieten, Berlin-New York 1975, c. 199 (CFHB, XI/1); тоже: Theophylacti Achridensis, Epistulae, c. 302-305. Стоит также заметить, что этот процесс был обоюдный, так как, напр., византийский военачальник, к слову турецкого происхождения, Татикий, намеревающийся взаимодействовать с силами I крестового похода в западных традициях, был описан как предатель (напр. Alberti Aquensis, Historia Hierosolomitana, [в:] Recueile des Historiens des Croisades, т. 4, Paris 1884, с. 417); в общих чертах по поводу взаимного восприятия: C. Asdracha, L'image de l'homme occidental à Byzance: le témoignage de Kinnamos et de Choniatès, „Byzantinoslavica”

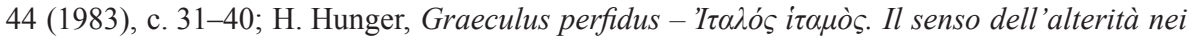
rapporti greco-romani ed italo-bizantini, Roma 1987; M. Whittow, How the east was lost: the background to the Komnenian reconquista, [в:] Alexios I Komnenos, ed. M. Mullet, D. Smythe, Belfast 1996, 55-59; A. Kazhdan, Franks and Latins in Byzantium: perception and reality from the eleventh to the twelfth century, [B:] The Crusades from the perspective of Byzantium and the Muslim world, ed. A. E. Laiou, R. P. Mottahedeh, Washington 2001, c. 83-100; E. Jeffreys, $\mathrm{M}$. Jeffreys, The «Wild beast from the West»: immediate literary reactions in Byzantium to the Second Crusade, [в:] The Crusades from the perspective of Byzantium and the Muslim world, c. 101-116; J. Dudek, Patrycjusz Swen..., c. 297.

${ }^{27}$ Можно привести также отрицательное мнение о латинах, а также о широко понимаемых чужих, выраженное провинциальным аристократом Кекавменом или высоким придворным Никитой Хониатом; Кекавмен, Советы и рассказы. Поучение византийского полководияа XI века, ред. Г. Г. Литаврин, Санкт-Петербург 2003, с. 294, 296; Nicetae Choniatae, Historia, c. $205,209$. 
Нет также никаких сомнений, что ортодоксальное христианство с самого начала было одним из главных элементов византийской общности ${ }^{28}$. Хорошим примером может послужить событие, описанное в «Житии св. Григория Декаполита», родившегося в Иринополе, на пограничье с халифатом ${ }^{29}$. Святой, по прибытии во фракийский порт Энос, то есть место где жили ромеи, был арестован местными властями и попал под следствие, во время которого акцентировал свою ортодоксию и поэтому был освобождён ${ }^{30}$. Пример св. Григория не исключение. В византийских источниках нередко доходит до отождествления понятий ромеи и христиане, напр., автор хроники X века, так называемой «Продолжение Феофана»,

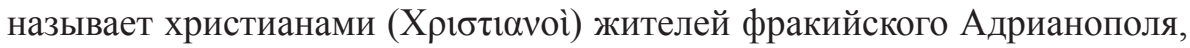
которых хан Крум переселил в глубь Болгарии ${ }^{31}$. Христиане - это также ромеи, которые, по призыву Романа Лакапина, встают на бой с болгарским царем Симеоном ${ }^{32}$.

Значение ортодоксального вероисповедания для ромейской общности подчёркивает также факт, что православие принимали, что вполне объяснимо, не только язычники или мусульмане, принадлежащие к византийской общественности ${ }^{33}$, но и латиняне, пришельцы с католического Запада ${ }^{34}$. Изменяли вероисповедание также монофизитские армяне, особенно лица продвигающиеся в византийской иерархии, хоть часто центральные власти обращались к этому средству, чтобы переломить армянское большинство

${ }^{28}$ H. Ahrweiler, Citoyens et étrangers dans l'Empire romain d'Orient, [в:] Da Roma alla terza Roma, 2: La nozione di «Romano» tra cittadinanza e universalità, c. 344-346; J. Gaudemet, Les Romains et les autres, [в:] Da Roma alla terza Roma, 2: La nozione di «Romano» tra cittadinanza e universalità, c. 27; J. Koder, Byzanz, die Griechen und die Romaiosyne - eine «Ethnogenese» der «Römer»?, [в:] Typen der Ethnogenesen unter besonderer Berücksichtigung der Bayern I, hrsg. W. Herwig et alii, Wien 1990, c. 104; тоже: H. Ahrweiler, L'idéologie politique de l'Empire byzantin, Paris 1975, c. 33-36, 63; P. Magdalino, The empire of Manuel I Komnenos, 1143-1180, Cambridge 1993, c. 316-412; V. Tăpkova-Zaimova, Y-a-t-il une notion..., c. 364.

${ }^{29}$ О жизни и личности св. Григория смотреть напр. F. Dvornik, La vie de saint Grégoire le Décapolite et les Slaves macédoniens au IX siècle, Paris 1926, c. 19-25.

${ }^{30}$ La vie de saint Grégoire, c. 54.

${ }^{31}$ Theophanes Continuatus, c. 216-218.

32 Там же, с. 402-403.

${ }^{33}$ C. M. Brand, The Turkish element..., c. 16; M. Balivet, Romanie byzantine et Pays de rûm turc, Istanbul 1994, c. 30-33; P. Bádenas, L'intégration..., c. 185.

${ }^{34}$ М. А. Курышева, Византийцы и норманны: проблемы симбиоза, „Византийский Временник” 65 (90) (2006), с. 150-159; тоже: D. M. Nicol, Symbiosis and integration. Some Greco-Latins families in Byzantium in the $11^{\text {th }}$ to the $13^{\text {th }}$ centuries, „Byzantinische Forschungen” 7 (1979), c. 113-135; A. Kazhdan, Franks and Latins ..., c. 93-100; E. Malamut, Les peuples..., с. 126-127; Е. А. Серен, Эмиграчия норманнов в Византию и «тагмы франков» (XI в.), „Античная древность и средние века” 32 (2001), с. 163-174. 
в восточных провинциях Империи ${ }^{35}$. Православие приобрело особое значение, как определитель принадлежности к ромейскому обществу, безусловно после событий 1204 года ${ }^{36}$, ведь именно тогда можно было заметить некоторые изменения в строении ромейской общности, которая с течением времени, и вместе со сжатием малоазиатских владений, всё более явно поворачивалась в сторону эллинских (греческих) традиций ${ }^{37}$.

Приведённые выше примеры позволяют предположить, что язык, культура и религия являлись очень существенными элементами, на которые опиралась византийская общественность, а принятие их позволяло иностранцам стать настоящими ромеями. Однако, следует подчеркнуть, что они окончательно не доказывают существование чувства этнического отличия.

В свою очередь, интересной предпосылкой, предполагающей существование такого чувства общности, могут быть слова приписанные Иоанном Скилицей, византийским историком XI века, Евстафию Дафномилу. Окружённый болгарами византийский стратег Дафномил якобы сказал: «Я, ромей, но ромей не из тех, проживающих во Фракии и Македонии, а в Малой Азии» ${ }^{38}$. Опуская все события связанные с приведенной фразой, стоит подчеркнуть, что Евстафий отождествляет себя с конкретным этносом проживающим в Малой Азии, а также во Фракии и Македонии. Более того, с точки зрения Дафномила, малоазиатские ромеи лучше. Естественно, не маловажным является также факт, что сам Иоанн Скилица был малоазиатского происхождения ${ }^{39}$. Следовательно, приведённые

${ }^{35} \mathrm{G}$. Dagron, Minorités ethniques et religieuse dans l'orient byzantin à la fin du Xe at au XI siècle: l'immigration syrienne, „Travaux et Mémoires” 6 (1976), c. 208-212; В. А. АрутюноваФиданян, Армяно-византийская контактная зона (X-XI вв.), Москва 1994, с. 78-92; N. Garsoïan, The problem of Armenian integration into the Byzantine Empire, [в:] Studies on the internal diaspora of the Byzantine Empire, ed. H. Ahrweiler, A. E. Laiou, Washington 1998, c. 53-124; K. Stopka, Armenia Christiana, Kraków 2002, с. 91-92; тоже: Г. Г. Литаврин, Византийское общество..., с. 165-166.

${ }^{36} \mathrm{H}$. Ahrweiler, L'expérience nicéenne, „Dumbarton Oaks Papers” 29 (1975), c. 24; M. Angold, The Fourth Crusade: event and context, London 2002, c. 193-203; тоже: J. Darrouzès, Le mémoire de Constantin Stilbès contre les Latins, „Revue des Etudes Byzantins” 21 (1963), c. 50-100.

${ }^{37}$ J. Irmscher, Nikä̈ als 'Zentrum des griechischen Patriotismus', ,Revue des Etudes Sud-Est Européennes" 8 (1970), c. 33-47; S. Runciman, The Last Byzantine Renaissance, Cambridge 1970, c. 15-23; A. E. Vacalopoulos, Origins..., passim; H. Ahrweiler, L'expérience..., c. 33, 36-40; idem, L'idéologie..., c. 62; M. Angold, Byzantine 'nationalism' and the Nicean Empire, „Byzantine and Modern Greek Studies” 1 (1975), c. 49-70; C. A. Trypanis, Les termes..., c. 434-435; C. M. Woodhouse, Gemistos Plethon. The last of Hellenes, Oxford 1986, c. 102-103; P. Magdalino, Hellenism..., c. 10, 17.

${ }^{38}$ Ioannis Scylitzae, Synopsis Historiarum, c. 362.

${ }^{39}$ K. Krumbacher, Geschichte der Byzantinischen Litteratur, München 1897, c. 364; G. Moravcsik, Byzantinoturcika, t. 1, Budapest 1958, c. 335; W. Seibt, Ioannes Skylitzes. Zur Person des Chronisten, „Jahrbuch der Österreichischen Byzantinistik” 25 (1976), c. 85; H. Hunger, Die 
слова могли бы быть свидетельством местного патриотизма и взаимного нерасположения между жителями европейских и азиатских территорий империи ${ }^{40}$. Однако, это также может свидетельствовать о существовании этнической общности ромеев.

Слова, приписанные византийским историком Дафномилу, описание Анной Комниной, в Алексиаде, иностранцев, изучающих греческий язык, а также напоминание Кегену, что его предложение негодно ромейской культуры - это довольно симптоматичные примеры, указывающие на существовании ромейской общности национального характера. В этом месте следует ещё подчеркнуть, что насколько маловероятно было возникновение народа, этнической группы, на территории обширной Римской империи или же в её восточной части, охватывающей народы с долговременной историей, с самостоятельным языком и культурой (Египет, Сирия), настолько более правдоподобным является формирование зародыша народности этой этнической группы, после потери Византией этих территорий. Территориально меньшее государство, более сплочённое, с точки зрения языка и культуры, могло легче ассимилировать пришельцев и передавать им свои государственные традиции. Возможным кажется также, достаточно точное, обозначение заселённой ромеями территории. Это была бы географическая Фракия (фемы Фракии и Македонии) и часть Малой Азии. Эти территории можно признать землей незатронутой варварской колонизацией, пространством, на котором императорская власть, практически никогда не перерывалась, где исключительная связь эллинизированного населения с Империей, а также его самоотождествление с римлянами-ромеями, прослеживаемое c IV века ${ }^{41}$, могли повлиять на возможное формирование ромейского

hochsprachliche profane Literatur der Byzantiner, т. 1, München 1978, c. 289; Jean Skylitzès, Empereurs de Constantinople, éd. B. Flusin, J.-Cl. Cheynet, Paris 2003, c. V.

40 Здесь стоит привести фрагмент работы Никиты Хониата, где он цитирует слова сказанные якобы Алексеем I Комниным жене, которая склоняла его измененить сукцессию

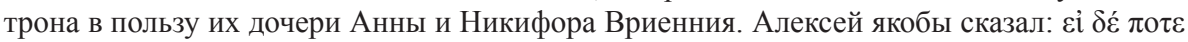

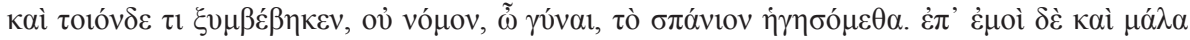

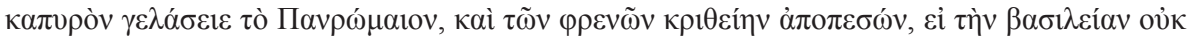

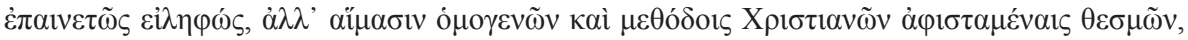

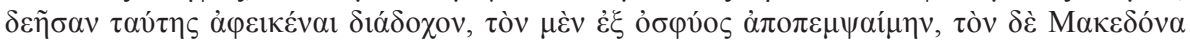

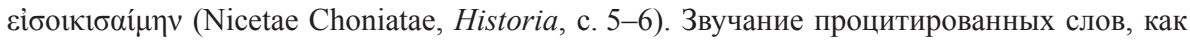
кажется, может носить характер пренебрежительный, тем более, что и Алексей Комнин, и Никита Хониат (M. E. Colona, Gli storici bizantini dal IV al XV secolo, I. Storici profani, Napoli 1956, c. 89; G. Moravcsik, Byzantinoturcika, c. 444; A. Kazhdan, S. Franklin, Studies on Byzantine literature of $11^{\text {th }}$ and $12^{\text {th }}$ centuries, Cambridge 1984, с. 256) были родом из Малой Азии; см. также: Г. Г. Литаврин, Византийское общество..., с. 170.

${ }^{41}$ Пальм сообщает, что уже в IV веке греческое население отождествлялось с понятием Romaioi (J. Palm, Rom, Römertum und Imperium in der griechischen Literatur der Kaiserzeit, Lund 1955); можно также добавить, что очевидное влияние на самоопределение грекоязычного населения как Romaioi имела тоже идея Константинополя как Нового Рима (M. Salamon, 
этноса. Заметное начало этого процесса можно было бы отнести к началу IX-X века, когда Византия оказалась на пороге новой эпохи, охватывая с одной стороны эллинизированные народы Малой Азии, а с другой европейских греков, правда находящихся под влиянием славян, которые, однако, постепенно поддавались процессу грецизации ${ }^{42}$. Несомненно, этот процесс был нарушен завоеванием сельджуками малоазиатских владений, однако деятельность Комниных возвратила империи часть Малой Азии, где преобладало эллинизированное население отождествляющее себя с ромеями. Но, поворотным пунктом, который, как кажется, преломил ромейский процесс возникновения народности, было поражение империи в результате действий IV крестового похода и его последствия: упомянутая уже, окончательная потеря Малой Азии, а также возвращение в последующих веках эллинских традиций ${ }^{43}$. Хотя, нужно отметить, что несмотря на далеко продвинутую грецизацию государства, никогда не наступило полное отождествление ромеев с древними греками ${ }^{44}$. Греческий элемент был несомненно многозначителен и влиял на многоэтническую популяцию империи, но не имел собственных централистических традиций. Следует также помнить, что исконные греческие территории на европейском континенте стали объектом интенсивного славянского заселения.

Rozwój idei Rzymu - Konstantynopola od VI do pierwszej połowy VI wieku, Katowice 1975; idem, Constantinopoli: «Nuova Roma»o «Roma Orientale»?, [в:] Itineraridi idee, uoimini e cose

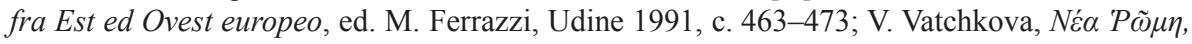
Roma Christiana et la naissance de l'Europe médiévale (IV-VI siècle), „Bulgarian Historical Review" 29 [2001] 3-4, c. 39-42).

${ }^{42}$ Напр. ясно говорит об этом Леон VI Философ, обсуждая политику своего отца

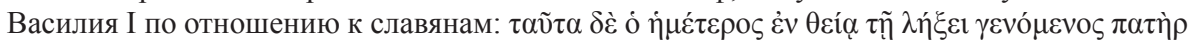

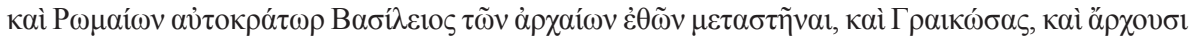

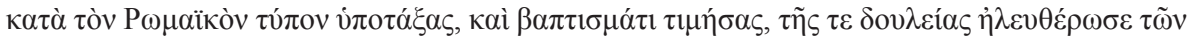
$\dot{\varepsilon} \alpha v \tau \tilde{\omega} v$ ả $\chi o ́ v \tau \omega v$ (Leonis imperatoris Tactica, PG 107, 969); G. Dagron, "Ceux d'en face». Les peuples étrangers dans les traités militaires byzantins, „Travaux et Mémoires” 10 (1987), c. 220-221; J. Koder, Byzanz..., c. 107-108.

${ }^{43}$ Стоит подчеркнуть, что среди византийских ученых уже в XII веке появлялись ссылки на эллинизм; в связи с ролью и значением эллинских традиции в Византии: A. Garzya, Visages de l'hellénisme dans le monde byzantin (VIe-XIIe siècles), „Byzantion” 55 (1985), c. 463-482; J. Koder, Byzanz..., c. 103; P. Magdalino, Hellenism..., c. 1-29; R. Beaton, Antique nation?..., c. 78, 87-93.

${ }_{44}^{44}$ Можно добавить, что до фактического отождествления греков с древними эллинами дошло лишь во время борьбы за независимость в начале XIX столетия; J. T. Kakridis, The Ancient Greeks and the Greeks of the War of Independence, „Balkan Studies” 4 (1963), c. 251-263; R. Beaton, Antique nation?..., c. 76-95. 


\section{Резюме}

Византия, наследник Римской империи, является отличным примером многоэтнического государства средневековой Европы. Многоэтническая Византия основывалась на римском праве, христианском вероисповедании и греческой культуре, а жители Империи считали себя законными преемниками civium Romanorum. Византийцем, то есть ромеем, официально был каждый житель, признающий ортодоксальное вероисповедание и принадлежащий к христианско-греческой культуре. Тем не менее открытым остаётся вопрос - имел ли в Византии этноним «ромей» исключительно упомянутое общественное значение, без этнического оттенка.

\section{Ключевые понятия}

Византия; Ромеи; этническая принадлежность

\section{Abstract}

\section{Romaioi - residents of the Empire or a nation in statu nascendi?}

Byzantium, the heir of the Roman Empire, is an excellent example of the multiethnic state of the medieval Europe. The multiethnic Byzantium was based on the Roman law, Christian faith and Greek culture, and the inhabitants of the Empire considered themselves as the legal successors of the civium Romanorum. The Byzantine, that is "Romei", was officially every resident confessing the orthodox religion and belonging to the Christian Greek culture. Nevertheless, the question remains as to whether the Byzantine word "Romei" refers to the general concern only, devoid of any ethnic element.

\section{Keywords}

Byzantium; Romaioi; ethnicity

\section{Библиография}

Арутюнова-Фиданян В. А., Армяно-византийская контактная зона (X-XI вв.), Москва 1994.

Василевский В. Г., Византия и печенеги (1048-1094), „Журнал Министерства Народного Просвещения" 164 (1872) № 11 и 12, с. 116-165, 243-332.

Златарски В., История на българската държсава през средните векове, София 1972.

Курышева М. А., Византийцы и норманны: проблемы симбиоза, „Византийский Временник” 65 (90) (2006), с. 150-162.

Литаврин Г. Г., Болгария и Византия в XI-XII вв., Мосвка 1960.

Литаврин Г. Г., Византийское общество и государство в X-ХІ вв, Москва 1977.

Серен Е. А., Эмиграичия норманнов в Византию и «тагмы франков» (ХІ в.), „Античная древность и средние века" 32 (2001), с. 163-174.

Ћурић И., Ромејски говор и језик Константина VII Порфирогенита, „Зборник Радова Византолошког Института" 24-25 (1986), с. 109-137.

Ahrweiler H., Citoyens et étrangers dans l'Empire romain d'Orient, [в:] Da Roma alla terza Roma, 2: La nozione di «Romano» tra cittadinanza e universalità, c. 343-350. 
Ahrweiler H., L'expérience nicéenne, „Dumbarton Oaks Papers” 29 (1975), c. 21-40.

Ahrweiler H., L'idéologie politique de l'Empire byzantin, Paris 1975.

Alberti Aquensis, Historia Hierosolomitana, [в:] Recueile des Historiens des Croisades, vol. 4, Paris 1884.

Anderson B., Imagined communities. Reflections on the origin and spread of nationalism, London-New York 1991.

Angold M., Byzantine 'nationalism' and the Nicean Empire, „Byzantine and Modern Greek Studies" 1 (1975), c. 49-70.

Angold M., The Fourth Crusade: event and context, London 2002.

Annae Comnenae, Alexias, rec. D. R. Reinsch, A. Kambylis, Berlin-New York 2001.

Asdracha C., L'image de l'homme occidental à Byzance: le témoignage de Kinnamos et de Choniatès, „Byzantinoslavica” 44 (1983), c. 31-40.

Bagge S., Nationalism in Norway in the Middle ages, „Scandinavian Journal of History” 20 (1995), c. 1-18.

Balivet M., Romanie byzantine et Pays de rûm turc, Istanbul 1994.

Beaton R., Antique nation? «Hellenes» on the eve of Greek independence and in twelfth-century Byzantium, „Byzantine and Modern Greek Studies” 31 (2007), c. 79-98.

Brand C. M, The Turkish element in Byzantium, eleventh-twelfth century, „Dumbarton Oaks Papers" 43 (1989), c. 1-25.

Cameron A., The Byzantines, Oxford 2006.

Charanis P., Ethnic changes in seventh-century Byzantium, „Dumbarton Oaks Papers” 13 (1959), c. 25-44

Charanis P., How Greek was the Byzantine Empire?, „Bucknell Review” 11 (1963), c. 101-116.

Charanis P., On the ethnic composition of byzantine Asia Minor in the thirteenth century, [в:] Studies offered in Honour of St. Kyriakides (Prosphora eis Stilpona P. Kyriakiden), Thessalonica 1953, c. 140-147.

Charanis P., Romiosyne as a concept for the interpretation of Greek history, „Byzantine Studies/Etudes Byzantines" 8-12 (1981-1985), c. 57-64.

Charanis P., The transfers of population as a policy in the Byzantine Empire, „Comparative Studies in Society and History an International Quarterly” 3 (1960) 1, c. 140-154.

Christophilopoulou A., Byzantine history, II: 610-867, Amsterdam 1993.

Chrysos E., The political identity in late antiquity and early Byzantium, [в:] Byzantium. Identity, image, influence, ed. C. Fledelius, Copenhagen 1996.

Collins R., Visigothic Spain 409-711, Oxford 2006.

Colona M. E., Gli storici bizantini dal IV al XV secolo, I. Storici profani, Napoli 1956.

Constantinus Porphyrogenitus, De Administrando Imperio, ed. Gy. Moravsik, R. J. H. Jenkins Washington 1967.

Corpus of Byzantine seals from Bulgaria, I, ed. I. Jordanov, Sofia 2003.

Coulton G. G., Nationalism in the Middle ages, „Cambridge Historical Journal” 5 (1935), c. $15-40$.

Dagron G., Aux origines de la civilisation byzantine: Langue de culture et langue d'État, „Revue Historique” 241 (1969), c. 23-56.

Dagron G., Formes et fonctions du pluralisme linguistique à Byzance (IXe-XIIe siècle), „Travaux et Mémoires” 12 (1994), c. 219-240.

Dagron G., Minorités ethniques et religieuse dans l'orient byzantin à la fin du Xe at au XI siècle: l'immigration syrienne, „Travaux et Mémoires” 6 (1976), c. 177-216.

Darrouzès J., Le mémoire de Constantin Stilbès contre les Latins, „Revue des Etudes Byzantins" 21 (1963), c. 50-100.

Dawkins R. M., The Greek language in the Byzantine period, [в:] Byzantium. An introduction to East Roman civilisation, ed. N. H. Baynes, H. St. L. B. Moss, Oxford 1948, c. 252-267. 
Diaconu P., Les Petchénègues au Bas-Danube, Bucareşt 1970.

Die Werke Liutprands von Cremona, Hrsg. J. Becker, Hannower und Leipzig 1915.

Dudek J., Ludy tureckie w Cesarstwie Bizantyńskim w latach 1025-1097, „Balcanica Posnanensia" 14 (2007), c. 83-124.

Dudek J., Nowa Patzynakia pomiędzy Wschodem i Zachodem. Z zapomnianych dziejów matego ludu, [w:] Opuscula archaeologica: opera dedicata in professorem Thaddeum Malinowski, red. W. Dzieduszycki, Zielona Góra 2007, c. 127-139.

Dudek J., Patrycjusz Swen (Sfenis) w bizantyńskiej wieży Babel, [в:] Mundus hominis - cywilizacja, kultura, natura, red. S. Rosik, P. Wiszewski Wrocław 2006, c. 291-305 (Acta Universitatis Wratislavensis, 2966, Historia CLXXV).

Dudek J., Pieczęć magistra Jana Kegena jako wyraz polityki Bizancjum wobec stepowców w połowie XI w., [в:] «Causa creandi»: o pragmatyce źródła historycznego, red. S. Rosik, P. Wiszewski, Wrocław 2005, c. 327-343 (Acta Universitatis Wratislaviensis. Historia).

Dupont C.,Sujets et citoyens sous le Bas-Empire romain de 312 à 565 après Jésus Christ, „Revue international des droits de l'antiquité” 20 (1973), s. 325-339.

Dvornik F., La vie de saint Grégoire le Décapolite et les Slaves macédoniens au IX siècle, Paris 1926.

Epistolae Karolini aevi (IV), Hrsg. E. Dümmler, E. Perels, Berlin 1974 (Monumenta Germaniae Historica. Epistolae, 6).

Eriksen T. H., Ethnicity and nationalism, London 1993.

Garsoïan N., The problem of Armenian integration into the Byzantine Empire, [в:] Studies on the internal diaspora of the Byzantine Empire, ed. H. Ahrweiler, A. E. Laiou, Washington 1998, c. 53-124.

Garzya A., Visages de l'hellénisme dans le monde byzantin (VIe-XII siècles), „Byzantion” 55 (1985), c. 463-482

Gautier P., Le typicon du sébaste Grégoire Pakurianos, „Revue des Etudes Byzantines” 42 (1984), c. 5-145.

Geary P. J., The myth of nations: the medieval origins of Europe, Princenton 2003.

Gellner E., Nations and nationalism, Oxford 1983.

Goria F., Romani, cittadinanza ed estensione della legislazione imperiale nelle costituzioni di Giustiniano, [в:] Da Roma alla terza Roma, 2: La nozione di "Romano" tra cittadinanza e universalità, Napoli 1984, c. 277-342.

Guenée B., État et nation en France au Moyen Age, „Revue Historique” 237 (1967), c. 17-30.

Herrin J., Byzantium: the suprising life of a Medieval Empire, London 2007.

Hobsbawm E. J., Nations and nationalism since 1780. Programme, myth, reality, Cambridge 1990.

Hunger H., Die hochsprachliche profane Literatur der Byzantiner, vol. 1, München 1978.

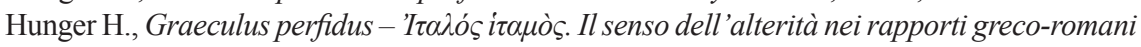
ed italo-bizantini, Roma 1987.

Ioannis Cinnami, Epitome rerum ab Ioanne et Alexio Comnenis gestarum, rec. A. Meineke, Bonnae 1836.

Ioannis Scylitzae, Synopsis Historiarum, rec. I. Thurn, Berlin-New York 1973.

Irmscher J., Nikä̈ als 'Zentrum des griechischen Patriotismus', „,Revue des Etudes Sud-Est Européennes" 8 (1970), c. 33-47.

Jeffreys E., Jeffreys M., The «Wild beast from the West»: immediate literary reactions in Byzantium to the Second Crusade, [в:] The Crusades from the perspective of Byzantium and the Muslim world, ed. A. E. Laiou, R. P. Mottahedeh, Washington 2001, c. 101-116. Jordanov I., Sceau d'archonte de Patzinakia du XIe siècle, „Etudes Balkaniques” 2 (1992), c. $79-82$. 
Kakridis J. T., The Ancient Greeks and the Greeks of the War of Independence, „Balkan Studies" 4 (1963), c. 251-263.

Kazhdan A., Franklin S., Studies on Byzantine literature of $11^{\text {th }}$ and $12^{\text {th }}$ centuries, Cambridge 1984.

Kazhdan A., Franks and Latins in Byzantium: perception and reality from the eleventh to the twelfth century, [в:] The Crusades from the perspective of Byzantium and the Muslim world, ed. A. E. Laiou, R. P. Mottahedeh, Washington 2001, c. 83-100.

Koder J., Byzanz, die Griechen und die Romaiosyne - eine «Ethnogenese» der «Römer»?, [в:] Typen der Ethnogenesen unter besonderer Berücksichtigung der Bayern I, hrsg. W. Herwig et alii, Wien 1990, c. 103-111.

Koht H., The dawn of nationalism in Europe, „The American Historical Review” 52 (1947), c. 265-280.

Krumbacher K., Geschichte der Byzantinischen Litteratur, München 1897.

Łukaszewicz A., Aegyptiaca Antoniniana. Działalność Karakalli w Egipcie (215-216), Warszawa 1993.

Macrides R., Dynastic marriages and political kinship, [в:] Byzantine diplomacy. Papers from the Twenty-fourth Spring Symposium of Byzantine Studies, Cambridge, March 1990, ed. J. Shepard, S. Franklin, Aldershot 1992, c. 263-280.

Magdalino P., Hellenism and Nationalism in Byzantium, [в:] idem, Tradition and Transformation in Medieval Byzantium, Aldershot 1991, XIV, c. 1-29.

Magdalino P., The empire of Manuel I Komnenos, 1143-1180, Cambridge 1993.

Malamut E., L'image byzantine des Petchénègues, „Byzantinische Zeitschrift” 88 (1995), c. $105-147$.

Malamut E., Les peuples étrangers dans l'idéologie impériale. Scythes et Occidentaux, [в:] L'étranger au Moyen Âge. Actes du XXXe Congrès de la SHMESP (Göttingen, 1999), Paris 2000, c. 119-132.

Michel Psellos, Chronographie, ed. E. Renauld, vol. 1, Paris 1926.

Mihăescu H., Byzance-foyer du Rayonnement de la culture romaine et de la langue latine dans le sud-est de l'Europe, „Byzantina” 6 (1974), c. c. 215-226.

Mirsky G. I., On ruins of empires. Ethnicity and nationalism in the former Soviet Union, London 1997.

Moravcsik G., Byzantinoturcika, t. 1, Budapest 1958.

Moreno L. A. G., Spanish Gothis consciousness among the Mozarabs in Al-Andalus (VIII-X th centuries), [в:] The Visigoths. Studies in culture and society, ed. A. Ferreiro, Leiden-Boston-Köln 1998, c. 303-323.

Nicetae Choniatae, Historia, rec. J. A. van Dieten, Berlin-New York 1975.

Nicol D. M., Symbiosis and integration. Some Greco-Latins families in Byzantium in the $11^{\text {th }}$ to the $13^{\text {th }}$ centuries, „Byzantinische Forschungen” 7 (1979), c. 113-135.

Oikonomidès N., L'«Unilinguisme» officiel de Constantinople byzantine (VII ${ }^{e}-X I I^{e}$ s.), „, $v \mu \mu \varepsilon 1 \kappa \tau \alpha ” 13$ (1999), c. 9-22.

Palm J., Rom, Römertum und Imperium in der griechischen Literatur der Kaiserzeit, Lund 1955. Runciman S., The Last Byzantine Renaissance, Cambridge 1970.

Salamon M., «Ojczyzny» plemion barbarzyńskich okresu Wędrówki Ludów, [в:] Pamiętnik XV Powszechnego Zjazdu Historyków Polskich, I, 1, red. J. Staszewski, Gdańsk- Toruń 1995 , c. $167-179$.

Salamon M., Constantinopoli: «Nuova Roma» o «Roma Orientale»?, [в:] Itineraridi idee, uoimini e cose fra Est ed Ovest europeo, ed. M. Ferrazzi, Udine 1991, c. 463-473.

Salamon M., Rozwój idei Rzymu - Konstantynopola od VI do pierwszej połowy VI wieku, Katowice 1975.

Schlumberger G., L'épopée byzantine à la fin du dixième siècle, t. 3, Paris 1905, c. 571. 
Seibt W., Ioannes Skylitzes. Zur Person des Chronisten, „Jahrbuch der Österreichischen Byzantinistik" 25 (1976), c. 81-86.

Stephenson P., Byzantium's Balkan frontier: a political study of the Northern Balkans, 900-1204, Cambridge 2000.

Stopka K., Armenia Christiana, Kraków 2002.

Symeonis Magistri et Logothetae, Chronicon, rec. S. Wahlgren, Berlin-New York 2006.

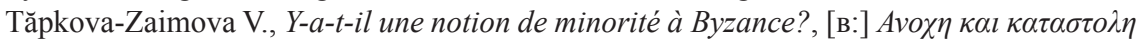

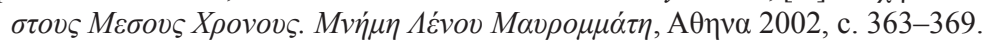

Teillet S., Des Goths à la nation gothique, Paris 1984.

Theophanes Continuatus, Ioannes Cameniata, Symeon Magister, Georgius Monachus, ed. I. Bekker, Bonnae 1838.

Theophylacti Achridensis, Epistulae, rec. P. Gautier, Thessalonique 1986

Thurman W. S., The application of subiecti to Roman citizens in the imperial laws of the later Roman Empire, „Klio” 52 (1970), c. 453-463.

Toufexis N., Diglossia and register variation in Medieval Greek, „Byzantine and Modern Greek Studies" 32 (2008), c. 203-217.

Trypanis C. A., Les termes «Romios», "Romiossini» et «Romania» pour les Grecs, [в:] Da Roma alla terza Roma, 3: Popoli e spazio romano tra diritto e profezia, Napoli 1986, c. 431-438.

Vacalopoulos A. E., Origins of the Greek nation. The Byzantine period, 1204-1453, New Brunswick 1970.

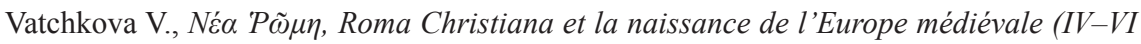
siècle), „Bulgarian Historical Review” 29 (2001) 3-4, c. 24-51.

Werner K. F., Les nations et le sentiment national dans l'Europe médiévale, „Revue Historique” 244 (1970), c. 285-304.

Whittow M., How the east was lost: the background to the Komnenian reconquista, [в:] Alexios I Komnenos, ed. M. Mullet, D. Smythe, Belfast 1996, c. 55-67.

Wipszycka E., Le nationalisme a-t-il existè dans l'Egypte byzantine?, „,The Journal of Juristic Papyrology" 22 (1992), c. 83-128.

Woodhouse C. M., Gemistos Plethon. The last of Hellenes, Oxford 1986.

Zakythinos D. A., Byzance: État national ou multinational?, „Deltion Christianikis Archaiologikis Etaireias" 4 (1980-1981) 10, c. 29-52.

Zientara B., Nationale Strukturen des Mittelalters. Ein Versuch zur Kritik der Terminologie des Nationalbewusstseins unter besonderer Berücksichtigung osteuropäischer Literatur, „Saeculum” 32 (1981), c. 301-316.

Zientara B., Świadomość narodowa w Europie Zachodniej w średniowieczu. Powstanie i mechanizmy zjawiska, [в:] Państwo, naród, stany w świadomości wieków średnich, red. A. Gieysztor, S. Gawlas, Warszawa 1990.

Zientara B., Świt narodów europejskich. Powstanie i rozwój świadomości narodowej na obszarze Europy pokarolińskiej, Warszawa 1996.

Zientara B., La conscience nationale en Europe occidentale au Moyen Age. Naissance et mécanismes du phénomène, „Acta Poloniae Historica” 46 (1982), c. 5-30. 
